\title{
Aripiprazole-associated tic in a schizophrenia patient
}

\author{
This article was published in the following Dove Press journal: \\ Neuropsychiatric Disease and Treatment \\ 30 March 2015 \\ Number of times this article has been viewed
}

\section{Xieli Guo ${ }^{1,2, *}$ \\ Dali Lu,* \\ Yugang Jiang'}

'Department of Neurosurgery, Second Xiangya Hospital of Central South University, Changsha, Hunan, People's Republic of China; ${ }^{2}$ Department of Neurosurgery, Jinjiang Hospital of Quanzhou Medical College, Jinjiang, Fujian, People's Republic of China; ${ }^{3}$ Department of Psychiatry, Xiamen Xianyue Hospital, Xiamen, Fujian, People's Republic of China

*These authors contributed equally to this work
Correspondence: Yugang Jiang

Department of Neurosurgery, Second

Xiangya Hospital of Central South

University, 139 Renmin Middle Road,

Changsha 4I00II, Hunan, People's

Republic of China

$\mathrm{Tel}+8615960795588$

Fax +86 I59 60795588

Email yugangjiang|23@।26.com

\begin{abstract}
Tic disorder, characterized by the presence of both motor and vocal tics is common in adolescents and adults. Antipsychotics including typical antipsychotics and atypical antipsychotics are generally recognized by experts as the most effective pharmacological treatment for tics. However, previous studies suggest that tic-like symptoms might manifest during treatment with atypical antipsychotics such as clozapine, quetiapine, but not aripiprazole. We present the first case, to our knowledge, of an adult schizophrenia patient who developed tics during treatment with aripiprazole.
\end{abstract}

Keywords: aripiprazole, antipsychotics, tic, schizophrenia, side effect

\section{Introduction}

Aripiprazole as an atypical antipsychotic is currently being used to treat schizophrenia. We report a case in which aripiprazole acted as a possible tic inducer during treatment of schizophrenia, although there have been several studies on the successful use of aripiprazole for the treatment of tic disorder in children and adolescents. ${ }^{1}$ This is probably the first such reported case, to our knowledge, in an adult schizophrenia patient.

\section{Case report}

A 30-year-old man diagnosed with DSM-IV schizophrenia, paranoid type, for 3 years. The patient had taken olanzapine $15 \mathrm{mg}$ daily initially for nearly 3 years, and his weight sharply jumped from 55 to $100 \mathrm{~kg}$ in the first 6 months. He was unwilling to take olanzapine for the first 3 months. However, when the medication was stopped, persistent psychotic symptoms recurred. So, he had taken olanzapine $15 \mathrm{mg} / \mathrm{d}$ again for the following two years, and his weight had jumped up to $112 \mathrm{~kg}$ when he came to our clinic. The patient finally refused to take this medicine any more. Compared with some other atypical antipsychotics, aripiprazole is associated with fewer metabolic disturbances. So we tapered his dose of olanzapine down to $5 \mathrm{mg} / \mathrm{d}$ quickly and administered aripiprazole $5 \mathrm{mg} / \mathrm{d}$ initially. Then, olanzapine was stopped and aripiprazole was titrated up to $10 \mathrm{mg} / \mathrm{d}$ on day 5 . However, he still experienced auditory hallucinations and reference delusions. So aripiprazole was increased progressively by $5 \mathrm{mg}$ every 4 days until his psychotic symptoms were controlled. His psychotic symptoms improved significantly when aripiprazole was titrated up to $25 \mathrm{mg} / \mathrm{d}$. Follow-up treatment was conducted once a month at the outpatient department. His family told us afterwards that there was occasional eye blinking and neck jerking from when the aripiprazole dose was titrated to $10 \mathrm{mg} / \mathrm{d}$. He could generally suppress these symptoms for a while, but they eventually reemerged and had been more frequent gradually when aripiprazole was titrated up to $25 \mathrm{mg} / \mathrm{d}$ at day 19 . When the patient came to our clinic again 1 month after he had taken aripiprazole initially, we used the Yale Global Tic Severity Scale to measure the severity of tic symptoms, and the score was 39. 
He had had childhood-onset simple motor tics since he was 10 years old, with varying characteristics, including blinking and shoulder shrugging. No abnormality was detected on a brain magnetic resonance imaging scan and electroencephalogram. Laboratory examination was normal: white blood cells, $7.12 \times 10^{9} / \mathrm{L}$; red blood cells, $4.50 \times 10^{9} / \mathrm{L}$; hemoglobin, $135.00 \mathrm{~g} / \mathrm{L}$; platelets, $150 \times 10^{9} / \mathrm{L}$; aspartate transaminase, $32 \mu \mathrm{g} / \mathrm{L}$; alanine transaminase, $31 \mu \mathrm{g} / \mathrm{L}$; anti-streptolysin $\mathrm{O}, 32 \mathrm{IU} / \mathrm{mL}$; and rheumatoid factor, negative. No family history of tic disorder was found.

Therefore, the dose of aripiprazole was quickly decreased to $5 \mathrm{mg} / \mathrm{d}$ in 1 week. These tic symptoms gradually improved and greatly resolved after 1-4 weeks. However, with a dose of aripiprazole $5 \mathrm{mg} / \mathrm{d}$, the psychotic symptoms appeared again. Aripiprazole was titrated to $25 \mathrm{mg} / \mathrm{d}$ again. Two weeks later, the psychotic symptoms resolved, but the tic symptoms occurred again. For that reason, medication was changed to risperidone $5 \mathrm{mg}$ daily to control his psychotic symptoms. At his follow-up visit 7 months later, he appeared to have no symptoms of schizophrenia and no tics in response to the treatment (risperidone, $5 \mathrm{mg} / \mathrm{d}$ ).

\section{Discussion}

Previous studies have shown that atypical antipsychotics such as risperidone, olanzapine, and ziprasidone are effective in treating patients with tic disorders. However, some reported cases suggest that tic-like symptoms might manifest during treatment with atypical antipsychotics such as clozapine, amisulpride, or quetiapine..$^{2-4}$ Compelling evidence suggests that increased central dopaminergic activity may exacerbate tics. Aripiprazole as an atypical antipsychotic is a partial dopamine and serotonin $2 \mathrm{~A}$ antagonist. Its potent serotonin $2 \mathrm{~A}$ blocking effect in presynaptic receptor may increase dopamine release, thus inducing tics. ${ }^{2,5}$ Secondly, as dopamine receptor hypersensitivity had been considered an underlying pathology of tic disorders, ${ }^{6}$ we cannot exclude the possibility that partial dopamine agonism of aripiprazole may contribute toward tics.

Interestingly, in our case, the tic symptoms worsened following a dose escalation and disappeared after a dose reduction. This indicated a dose-dependent side effect.
Previous cases also supported it. Lindenmayer et $\mathrm{al}^{7}$ reported three cases of tic-like symptoms after treatment with clozapine. All of those three patients developed tics seriously with a high dose of clozapine, with gradual improvement of these symptoms during a reduction of the clozapine dose. Likewise, Chen et al reported a case in which quetiapine $150-600 \mathrm{mg} / \mathrm{d}$ acted as a possible tic inducer during treatment of bipolar disorder, and the tic-like symptoms quickly resolved in 1-2 weeks when the dose of quetiapine was decreased to $50 \mathrm{mg} / \mathrm{d} .^{4}$ Successful management may be possible by reducing dosage or by adding valproate, clonazepam, or other antipsychotics. ${ }^{3,4,8}$ Also, alpha-2 agonists including clonidine and guanfacine can be used as the first-line pharmacological treatments for tics because of their more benign safety profile. ${ }^{9}$

In all, as it can be detrimental to treatment adherence, clinicians should be aware of the possibility that patients treated with a high dose of aripiprazole may develop tic-like symptoms.

\section{Disclosure}

The authors report no proprietary or commercial interest in any product mentioned or concept discussed in this article.

\section{References}

1. Yoo HK, Joung YS, Lee JS, et al. A multicenter, randomized, doubleblind, placebo-controlled study of aripiprazole in children and adolescents with Tourette's disorder. J Clin Psychiatry. 2013;74:e772-e780.

2. Kinon BJ, Lieberman JA. Mechanism of action of atypical antipsychotic drugs: a critical analysis. Psychopharmacology. 1996;124:2-34.

3. Lin CL, Shiah IS, Yeh CB, Wan FJ, Wang TS. Misulpride related tic like symptoms in an adolescent schizophrenic. Prog Neuropsychopharmacol Biol Psychiatry. 2006;30:144-146.

4. Chen S, Gong H, Chen X. Quetiapine-related tic in a pediatric bipolar patient. J Child Adolesc Psychopharmacol. 2014;24:165.

5. Greenaway M, Elbe D. Focus on aripiprazole: a review of its use in child and adolescent psychiatry. J Can Acad Child Adolesc Psychiatry. 2009;18:250-260.

6. Leckman JF. Tourette's syndrome. Lancet. 2002;360:1577-1586.

7. Lindenmayer JP, Da Silva D, Buendia A, Zylberman I, Vital-Herne M. Tic-like syndrome after treatment with clozapine. Am J Psychiatry. 1995;152:649.

8. Reid SD. Neuroleptic-induced Tardive Tourette treated with clonazepam: a case report and literature review. Clin Neuropharmacol. 2004;27:101-104.

9. Weisman H, Qureshi IA, Leckman JF, Scahill L, Bloch MH. Systematic review: pharmacological treatment of tic disorders-efficacy of antipsychotic and alpha-2 adrenergic agonist agents. Neurosci Biobehav Rev. 2013;37:1162-1171.
Neuropsychiatric Disease and Treatment

\section{Publish your work in this journal}

Neuropsychiatric Disease and Treatment is an international, peerreviewed journal of clinical therapeutics and pharmacology focusing on concise rapid reporting of clinical or pre-clinical studies on a range of neuropsychiatric and neurological disorders. This journal is indexed on PubMed Central, the 'PsycINFO' database and CAS,

\section{Dovepress}

and is the official journal of The International Neuropsychiatric Association (INA). The manuscript management system is completely online and includes a very quick and fair peer-review system, which is all easy to use. Visit http://www.dovepress.com/testimonials.php to read real quotes from published authors. 